\section{Summary}

The chromosomes were examined in preparations made directly (without culture) from biopsy material from the affected area in eight cases with presumptive precancerous change (carcinoma-in-situ or dysplasia) of the cervix uteri and one of the vagina. The eight cervical lesions were entirely intraepithelial, but the vaginal one was associated with a small invasive carcinoma.

In every case there were variations in the chromosome count, sometimes with abnormal modal values suggesting new clone formation. In most of those cells in which karyotype analysis could be performed there was an abnormal distribution in the Patau groups with little evidence of structural changes. In one case an abnormal clone of cells was identifiable by a long marker chromosome.

It is concluded that extensive chromosomal rearrangements and adaptations are taking place in precancerous epithelium, often for years before the onset of carcinoma.

We wish to thank our colleagues who have supplied us with the biopsy material: Professor J. Chassar Moir, Mr. J. A. Stallworthy, Mr. W. Hawksworth, Mr. M. P. Embrey, Mr. K. V. Cooper, and Dr. P. F. Giles, in the United Oxford Hospitals ; Mr. C. J. Champ, at Amersham General Hospital ; and Mr. D. N. S. Robertson and Mr. E. G. G. Jonas, at Stoke Mandeville Hospital, Aylesbury. We are also indebted to the pathologists who have supplied us with sections: Dr. R. H. Cowdell, Dr. M. S. Dunnill, Dr. W. C. D. Richards, Dr. W. A. Aherne, Dr. H. J. Harris, and Dr. C. R. Tribe. We acknowledge with thanks the photographic assistance of Dr. T. Parry and Mr. R. L. Wilkins, and the technical assistance of Mrs. T. Wilkins, Mrs. M. Ayres, and Mrs. B. M. Allardyce. Two of us (M. M. B. and A. I. S.) were supported by the British Empire Cancer Campaign.

\section{REFERENCES}

Boddington, M. M., Cowdell, R. H., and Spriggs, A. I. (1960). Brit. F. Cancer, 14, 151

Grundmann, E., Hillemanns, H. G., and Rha, K. (1961). Z. Krebsforsch., $64,390$.

Hauschka, T. S. (1963). Exp. Cell Res., Suppl. No. 9, p. 86.

International Committee on Histological Terminology for Lesions of the Uterine Cervix ; Report on Proceedings (1961). Proceedings of First International Congress of Exfoliative Cytology, Vienna, p. 283.

Laumonier, R., Laquerrière, R., Nobecourt, J., and Hemet, J. (1963). Ann. Anat. path., 8, 275 .

Lubs, H. A., and Clark, R. (1963). New Engl. F. Med., 268, 907.

Makino, S., Ishihara, T., and Tonomura, A. (1959). Z.' Krebsforsch., 63, 184.

Reid, B. L., and Singh, S. (1960). F. nat. Cancer Inst., 25, 1291.

Richart, R.' M., and Corfman, P. A. (1964). Science, 144, 65.

Sandritter W. and Fischer, R. (1961). Proceedings of First Inter national Congress of Exfoliative Cytology, Vienna, p. 189.

Spriggs, A. I. (1964). Brit. F. Radiol., 37, 210.

Spriggs, A. I. (1964). Brit. F. Radiol., 37, 210. (1962a). Lancet, 1, 1383. - Boddington, M. M., and Clarke, C. M. (1962.

Steele, H. D., Manocha, S. L., and Stich, H. F. (1963). Ibid., 2, 1314

Stich, H. F. (1960). F. nat. Cancer Inst., 24, 1283.

Wakonig-Vaartaja, R. (1962). Brit. F. Cancer, 16, 616.

- (1963). Aust. N.Z. F. Obstet. Gynaec., 3, 170.

\title{
Role of the Ankle-jerk in the Diagnosis and Management of Thyroid Disease
}

\author{
D. W. MILES,* M.B., CH.B., B.SC. ; I. SURVEYOR, † M.B., M.R.C.P.
}

Brit. med. F., 1965, 1, 158-161

Changes in the time of contraction and relaxation of the anklejerk in thyroid disease have been claimed to be of diagnostic importance (Lambert et al., 1951 ; Lawson, 1958 ; Fogel et al., 1962 ; Sherman et al., 1963). There is still some dispute on whether the phase of contraction of the muscle is altered or whether the changes observed occur only during the relaxation phase. Fogel et al. (1962) reported that the "musclecontraction phase occurs promptly regardless of the thyroid state of the individual." Sherman et al. (1963) were unable to confirm this.

Previous studies on the usefulness of the ankle-jerk have been made on patients in whom the clinical diagnosis was beyond dispute (Lawson, 1958 ; Sherman et al., 1963). The present work was undertaken to assess the value of timing the anklejerk as a diagnostic test in doubtful as well as in definite disturbances of thyroid function.

Comparisons are made between the jerk times, clinical assessment, and radioactive-iodine uptake.

The measurements of jerk times during the treatment of patients with myxoedema and thyrotoxicosis are illustrated and the value of this test in their management is discussed. Changes in the jerk times in panhypopituitarism after the use of thyroidstimulating hormone and in normal subjects after the administration of large doses of triiodothyronine are also reported.

\footnotetext{
* Registrar, Department of Medicine, the University of Leeds. + Registrar, Department of Nuclear Medicine, the General Infirmary at Leeds.
}

\section{Subjects}

The 131 normal subjects studied were composed of volunteers from the hospital staff and patients suffering from minor trauma who attended the casualty department. One normal subject was rejected because satisfactory recordings were not obtained. Two patients with unsatisfactory ankle-jerks were rejected from this study.

Twenty-eight men and 137 women aged from 14 to 71 years (Table I) were referred for assessment and radioactive-iodine uptake. These included 21 patients previously treated with radioactive iodine, eight treated by partial thyroidectomy, and three treated by both surgery and radioactive iodine.

TABLE I.-Age and Sex Distribution of the 165 Patients Referred for

\begin{tabular}{|c|c|c|c|c|c|c|c|c|}
\hline Age: & $10-19$ & $20-29$ & $30-39$ & $40-49$ & $50-59$ & $60-69$ & $70+$ & Total \\
\hline 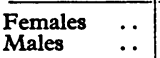 & $\begin{array}{l}6 \\
0\end{array}$ & $\begin{array}{r}14 \\
3\end{array}$ & 24 & $\begin{array}{r}29 \\
7\end{array}$ & $\begin{array}{r}43 \\
7\end{array}$ & $\begin{array}{r}18 \\
8\end{array}$ & $\begin{array}{l}3 \\
0\end{array}$ & $\begin{array}{r}137 \\
28\end{array}$ \\
\hline
\end{tabular}

\section{Methods}

The patients were graded clinically and placed in the following groups: (1) probably thyrotoxic ; (2) possibly thyrotoxic ; (3) probably normal ; (4) possibly hypothyroid ; and (5) probably hypothyroid. 
The neck uptake of radioactive iodine was measured 24 hours after the oral dose, using a thallium potassium iodide crystal (15 by $1 \frac{1}{8}$ in. ; 4.1 by $2.9 \mathrm{~cm}$.). Venous blood was sampled at this time and the radioactive plasma protein-bound iodide was estimated. The neck uptake was interpreted in conjunction with the plasma protein-bound ${ }^{131} \mathrm{I}$ and recorded as high, normal, or low (Table II).

The ankle-jerks were measured separately before the operator knew either the results of the clinical assessment or the uptake studies. They were elicited using a patella hammer and were recorded by a device similar to that described by Smart and Robson (1963) (Fig. 1). It consists of a "drop-foot" splint incorporating a potentiometer bridge connected to a D.C. amplifier and pen recorder using a paper speed of $60 \mathrm{~mm} . / \mathrm{sec}$.

The contraction phase was measured as the time from the beginning of the stimulus artifact to the point of greatest amplitude-called the tap-to-peak time. The time from the beginning of the stimulus to the point on the relaxation phase of the recording, which is half the amplitude, the tap-to-halfrelaxation time, was used as the most satisfactory measurement of the relaxation phase (Lambert et al., 1951 ; Fogel et al., 1962 ; Sherman et al., 1963). Fig. 2 illustrates some typical results.

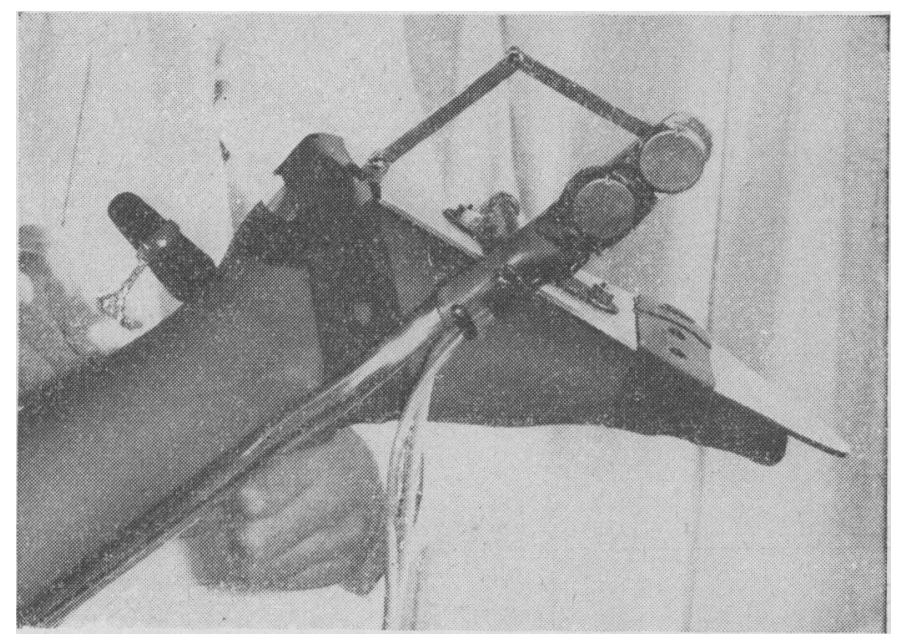

FIG. 1.-The patient is lying prone with the leg supported by the examiner's hand above the ankle-joint.

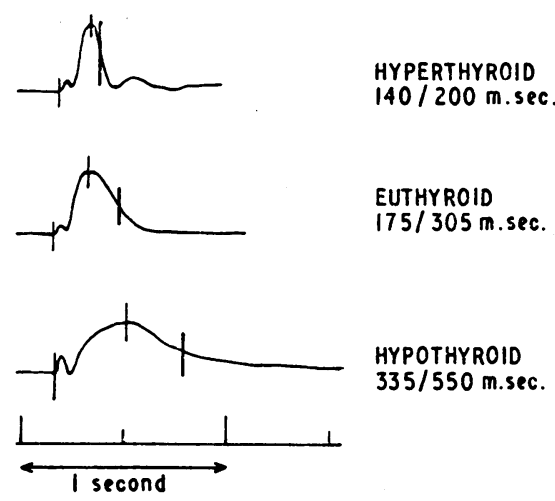

Fig. 2.-Typical results obtained from three different patients.

The tap-to-peak and tap-to-half-relaxation times were measured and the mean of six measurements was taken. The ankle-jerks were elicited when the patients were relaxed, and consecutive readings did not vary by more than $15 \mathrm{msec}$. in the fast jerks, though this increased to $30 \mathrm{msec}$. in the prolonged jerks.

\section{A. Normal Range}

Results

There was no difference between the jerk times recorded in normal males and females and no significant change with age.
The mean results in 131 normal subjects (49 males, 82 females) were tap-to-peak 187 msec. (S.D. $22 \mathrm{msec}$.) and tap-to-halfrelaxation $289 \mathrm{msec}$. (S.D. $22 \mathrm{msec}$.). The normal range is taken as $145-230 \mathrm{msec}$. and $240-340 \mathrm{msec}$. for each, respectively (mean \pm 2 S.D.).

\section{B. Comparison of Jerk Times and ${ }^{131} \mathbf{I}$ Uptake}

The jerk times are plotted against the 24-hour ${ }^{131} \mathrm{I}$ uptake and the results shown in Figs. 3 and 4 . The correlation coefficient for the tap-to-peak graph (Fig. 3) was $r=0.77$ (S.E.

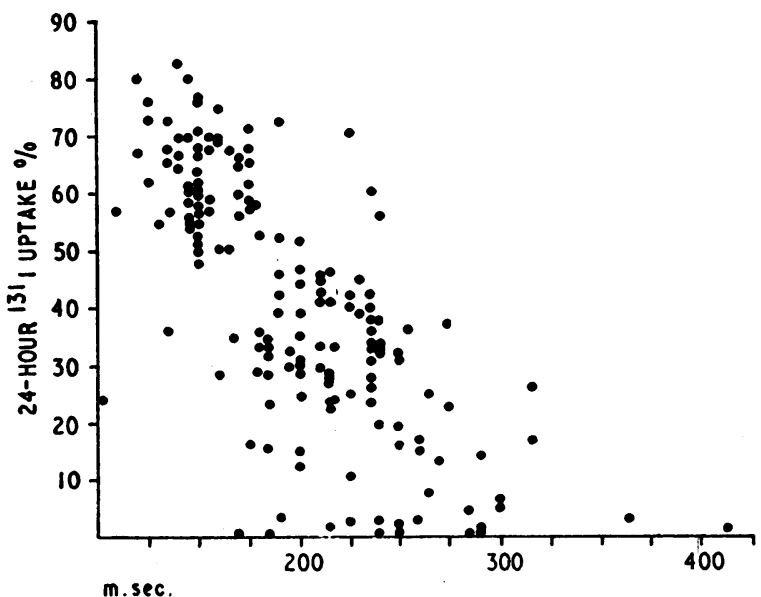

Fig. 3.-The tap-to-peak (msec.) is plotted against the 24-hour radioactive-iodine uptake in 165 patients. Correlaton co-

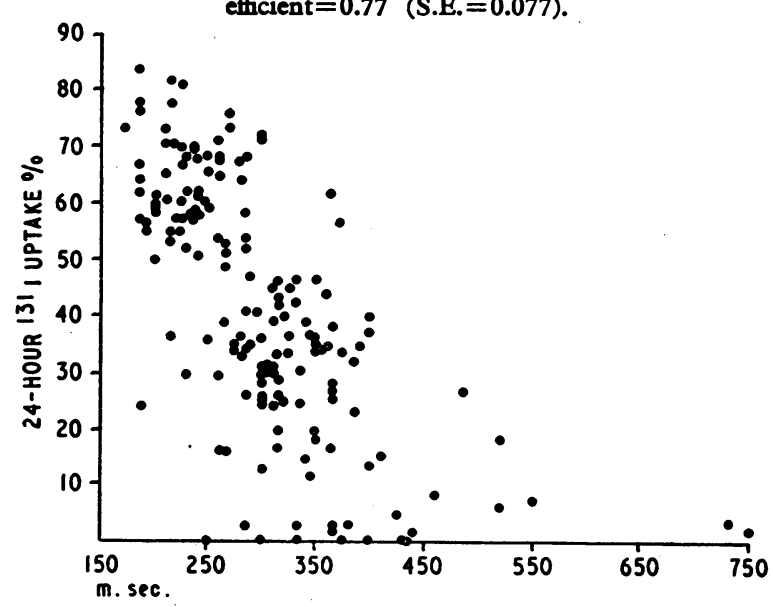

Fig. 4. - The tap-to-half-relaration (msec.) is plotted agalnst the 24-hour radioactive-iodine uptake in 165 patients. Correlation coefficient $=0.78($ S.E. $=0.077$ )

of the coefficient $=0.077$ ). This confirms that the contraction phase is altered by the thyroid hormones. The correlation coefficient for the tap-to-half-relaxation was $r=0.78$ (S.E. 0.077).

The jerk times and the ${ }^{131} \mathrm{I}$ uptake gave similar results in 127 (77\%) patients, as are shown in Table II. (This consisted of

TABLB II.-Ferk Times and 24-Hour ${ }^{121}$ I Uptake

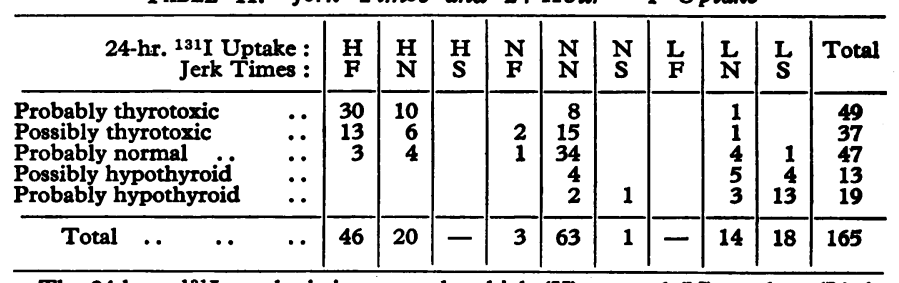

The 24-hour ${ }^{131}$ I uptake is interpreted as high (H), normal (N), or low (L) in conjunction with the plasma protein-bound ${ }^{131} \mathrm{I}$.

The jerk times are recorded as fast (F), normal (N), or slow (S) by interpreting both tap-to-peak and tap-to-half-relaxation results together; for example, if the tap-to peak was fast and the tap-to-half-relaxation was at the upper limit of normal this 
30 patients with a high uptake and fast jerk times and eight with a normal uptake and normal jerk times in the probably thyrotoxic group. In the possibly thyrotoxic group 13 patients had a high uptake and fast jerks and 15 normal uptake and normal jerk times. In the probably normal group 34 patients had normal results in both tests, three a high uptake and fast jerk times, and one a low uptake and slow jerk times. In the possibly hypothyroid and probably hypothyroid groups 4 and 13 patients respectively had a low uptake and slow jerks, while four and two patients respectively had normal results.)

\section{Comparisons with Clinical Assessment}

(a) Comparison Between Clinical Assessment and ferk Times. - The clinical assessment was supported by the results of the ankle-jerk in $105(64 \%)$ patients. (This series is composed of 30 patients in the probably thyrotoxic group and $15(13+2)$ patients in the possibly thyrotoxic group. In the probably normal group 42 patients had normal jerk times $(4+34+4)$ and four patients had slow jerks in the possibly hypothyroid group with $14(13+1)$ patients with slow jerks in the probably hypothyroid group.) (Table II.)

(b) Comparison Between Clinical Assessment and ${ }^{131} I$ Uptake. -In $119(72 \%)$ of the patients the clinical assessment is supported by the results of the ${ }^{131}$ I-uptake studies. (This series consists of $40,19,34,9$, and 16 patients in each group respectively.) (Table II.)

(c) Comparison Between Clinical Assessment, ferk Times, and ${ }^{131}$ I Uptake.-The clinical assessment was confirmed by both the ${ }^{131} \mathrm{I}$ uptake and the jerk times in $94(57 \%)$ patients. (This series is composed of $30,13,34,4$, and 13 patients respectively in the five clinical groups.) (Table II.)

\section{Use of Jerk Times in Management of Patients}

This is illustrated by referring to an individual patient. In an 18-year-old girl a clinical diagnosis of thyrotoxicosis was made. Investigations showed jerk times of $140 / 225$ msec. (tapto-peak/tap-to-half-relaxation) and a 24 -hour ${ }^{13}{ }^{1}$ I uptake of $68 \%$ of the administered dose with protein-bound ${ }^{131} \mathrm{I}$ of $1 \%$ confirming the diagnosis. She was treated with carbimazole 60 $\mathrm{mg}$./day, and the jerk times slowed to $190 / 275$ msec. though they subsequently speeded up to $135 / 215 \mathrm{msec}$., requiring an increase of the carbimazole to $80 \mathrm{mg}$./day. This was replaced by iodine for 10 days pre-operatively, and the day before operation the jerk times were $200 / 285 \mathrm{msec}$. A partial thyroidectomy was performed and the patient enjoyed good health for a month. After this she started to gain weight and felt lethargic. Jerk times were recorded as $250 / 385 \mathrm{msec}$., confirming the clinical suspicion that she was hypothyroid, and treatment with L-thyroxine was started: $0.05 \mathrm{mg}$. daily at first, gradually increased to $0.1 \mathrm{mg}$. t.d.s. The jerk times have subsequently returned to a normal value of $165 / 300 \mathrm{msec}$. (Table III).

Table III.-Management of the Patient Described in Section D

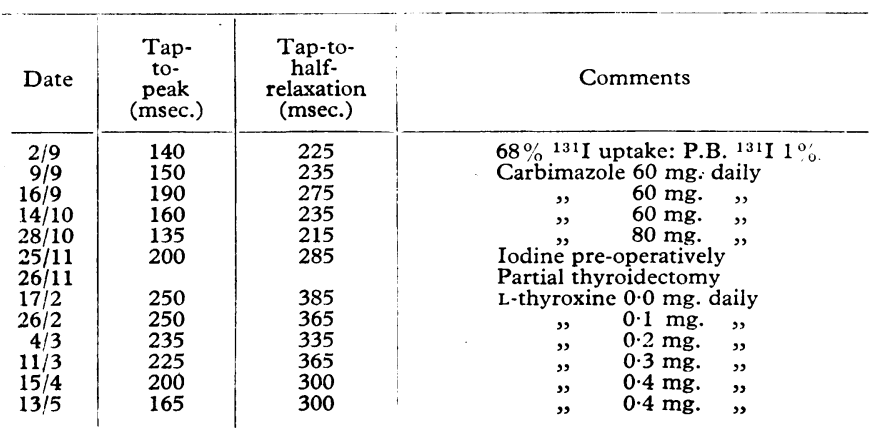

\section{E. Hypopituitarism}

In a patient with panhypopituitarism investigations showed a 24-hour ${ }^{131} \mathrm{I}$ uptake of $16.8 \%$ (protein-bound ${ }^{131} \mathrm{I}=0.26 \%$ ), and jerk times of $260 / 410 \mathrm{msec}$. After five days' treatment with 10 units daily of thyroid-stimulating hormone the ${ }^{131}$ I uptake increased to $59.8 \%$ and the jerk times to $200 / 295 \mathrm{msec}$.

\section{F. Effect of Triiodothyronine in Normal Subjects}

Triiodothyronine was administered to three normal subjects. After the administration of large doses (up to $400 \mu \mathrm{g}$./day) the jerk times were observed to shorten. For example, one of us (I. S.) had jerk times of $200 / 285$ msec. which changed to $140 / 225$ msec. after 10 days' treatment, starting with a dose of $40 \mu \mathrm{g}$./day and increasing this to $200 \mu \mathrm{g}$./day for the last five days. The jerks subsequently returned to normal over the course of the next four days. Over the same period the B.M.R. changed from $-5 \%$ to $+20 \%$ (Table IV).

TABLE IV.-Effect of Large Doses of Trïodothyronine on Ferk Times of a Normal Subject

\begin{tabular}{|c|c|c|c|c|}
\hline Date & $\begin{array}{c}\text { Tap- } \\
\text { to-peak } \\
\text { (msec.) }\end{array}$ & $\begin{array}{l}\text { Tap-to- } \\
\text { half-relaxation } \\
\text { (msec.) }\end{array}$ & B.M.R. & Triiodothyronine \\
\hline $\begin{array}{l}17 / 4 \\
18 / 4 \\
19 / 4 \\
20 / 4 \\
22 / 4 \\
23 / 4 \\
24 / 4 \\
25 / 4 \\
26 / 4 \\
27 / 4 \\
28 / 4 \\
29 / 4 \\
30 / 4 \\
1 / 5 \\
2 / 5 \\
3 / 5 \\
4 / 5 \\
8 / 5 \\
30 / 5\end{array}$ & $\begin{array}{l}200 \\
195 \\
205 \\
205 \\
200 \\
205 \\
190 \\
165 \\
160 \\
175 \\
\\
150 \\
150 \\
140 \\
140 \\
160 \\
175 \\
180 \\
200\end{array}$ & $\begin{array}{l}285 \\
275 \\
290 \\
295 \\
300 \\
295 \\
280 \\
265 \\
255 \\
270 \\
\\
250 \\
245 \\
240 \\
225 \\
245 \\
280 \\
280 \\
275\end{array}$ & $-5 \%$ & $\begin{array}{r}40 \mu \mathrm{g} . \\
40 \mu \mathrm{g} . \\
100 \mu \mathrm{g} . \\
100 \mu \mathrm{g} . \\
100 \mu \mathrm{g} . \\
200 \mu \mathrm{g} . \\
200 \mu \mathrm{g} . \\
200 \mu \mathrm{g} . \\
200 \mu \mathrm{g} . \\
200 \mu \mathrm{g} .\end{array}$ \\
\hline
\end{tabular}

\section{Discussion}

These results confirm the observations of Sherman et al. (1963) and show a definite change in the contraction phase in patients with thyroid dysfunction.

The measurement of jerk times from the beginning of the stimulus artifact has been criticized (Buller, 1963). The duration of the artifact is the time taken by the neural reflex arc, and is increased in hypothyroid subjects (Lambert et al., 1951). The inclusion of this time does not affect the accuracy of the test.

The changes in jerk times which have been observed in normal subjects following the administration of large doses of triiodothyronine and in panhypopituitarism following the administration of thyroid-stimulating hormone suggest that the changes observed are due to the thyroid hormones acting on the muscle itself. Both the effect of secondary temperature changes in muscles and the possibility of neuronal afterdischarge have been examined. The variations in the temperature of the muscles observed in thyroid disease are not sufficient to account for the changes recorded in the jerk times (Lambert et al., 1951).

In previous assessments of the usefulness of the ankle-jerk the groups studied have been carefully selected (Lawson, 1958 ; Sherman et al., 1963). For example, Sherman et al. (1963) studied 53 hypothyroid, 40 hyperthyroid, and 255 euthyroid patients. "The diagnosis of hyperthyroidism or hypothyroidism was based on appraisals by ward physicians and nembers of the endocrinology section supported by the results 
of at least two of the conventional tests of thyroid function." By choosing only cases in which there was no difficulty in making the clinical diagnosis their series does not give any information on the borderline group of patients in whom the clinical diagnosis is difficult and investigations may also be indecisive. In the present series 97 patients (groups 2, 3, and 4) were in the borderline category because even in those patients clinically diagnosed as probably normal the referring physician had raised the possibility of thyroid dysfunction. From the results shown in Table II it can be seen that there is a better correlation between the jerk times and the ${ }^{131}$ I uptake (77\% agreement) than clinical assessment and either jerk times or the ${ }^{131}$ I uptake. This demonstrates that the jerk times are a useful test in borderline as well as in definite disturbances of thyroid function.

The advantage of this test is its simplicity. It is inexpensive and the results are immediately available. Useful information can be obtained in patients in whom ${ }^{131} \mathrm{I}$ studies are unsatisfactory or difficult to interpret ; for example, after treatment with radioactive iodine, or thyroidectomy, with antithyroid drugs or sulphonylureas; if the patient has been ingesting large doses of iodine, as in some cough mixtures; or after contrast radiography. It may be used in pregnancy or in situations where ${ }^{131}$ I facilities are not available. The main advantage is that it is an objective guide to the efficacy of therapy in both hypothyroid and thyrotoxic subjects.

Apart from the drugs already mentioned high doses of salicylates, dexamphetamine, A.C.T.H. and steroids, and oestrogens are said to shorten the duration of the jerk times (Lawson, 1958).

Muscle disorders such as dystrophia myotonica have been observed to shorten the jerk times (Lambert et al., 1951), and sarcoidosis (Richards, 1962) and neurosyphilis (Simpson et al., 1963) may prolong them.

Disturbances of the central nervous system may alter the amplitude of the jerks but do not alter the times in some conditions (Sherman et al., 1963). However, in view of the changes observed in neurosyphilis the interpretation of jerk times in patients with organic neurological disease must be tentative.

\section{Summary}

The ankle-jerk has been measured with the method described by Smart and Robson (1963). The results recorded from 131 subjects gave a normal range of $145-230 \mathrm{msec}$. and $240-340$ msec. for the tap-to-peak and tap-to-half-relaxation measurements respectively.

The ankle-jerk times obtained in 165 patients with thyroid disease are compared with an independent clinical assessment and with the neck uptake of radioactive iodine (interpreted in conjunction with the protein-bound radioactive iodine).

Both the contraction and the relaxation phases of the anklejerks are affected by thyroid hormones, either measurement being equally satisfactory for use in the assessment and management of thyroid disease. This is illustrated by reference to the jerk times in a patient with thyrotoxicosis, in one with panhypopituitarism, and in three normal subjects after the administration of triiodothyronine.

The limitations of the test are discussed, and it is concluded that the test is a simple inexpensive way of diagnosis and the only objective means, apart from the B.M.R., of assessing response to treatment.

We wish to express our thanks to Dr. D. Taverner and Dr. C. J. Hayter for their help and criticisms. We also thank Mr. B. Harvey for his technical assistance.

\section{REFERENCES}

Buller, A. J. (1963). Lancet, 1, 443.

Fogel, R. L., Epstein, J. A., Stopak, J. H., and Kupperman, H. S. (1962). N.Y. St. Epstein, J. A., Stopak

N.Y. St. F. Med., 62, 1159. L. O., Beckett, S., and Mederos, L. $O$. (1951). f. clin. Endocr., 11, 1186.

Lawson, J. D. (1958). New Engl. ₹. Med., 259, 761.

Richards, A. G. (1962). Canad. med. Ass. 7., 86, 32

Sherman, L., Goldberg, M., and Larson, F. C. (1963). Lancet, 1, 243. Simpson, G. M., Blair, J. H., and Nartowicz, G. R. (1963). New Engl. 7. Med., 268, 89.

Smart, G. A., and Robson, A. M. (1963). Lancet, 1, 363.

\title{
Effect of Variation in Dietary Calcium on Plasma Concentration and Urinary Excretion of Calcium
}

\author{
I. J. MACFADYEN, ${ }^{*}$ M.B., CH.B., D.oBsT.R.C.O.G. ; B. E. C. NORDIN, $\dagger$ M.D., PH.D., M.R.C.P. ; \\ D. A. SMITH, $\ddagger$ M.B., CH.B., B.SC., M.R.C.P.ED. ; D. J. WAYNE,*\| M.A., B.M., B.CH., M.R.C.P., M.R.C.P.ED. ; \\ S. L. RAE,§ F.I.M.L.T.
}

Brit. med. F., 1965, 1, 161-164

The constancy of the plasma calcium in normal persons despite wide variations in calcium intake is well recognized, and early suggestions that it could be influenced by dietary intake have been largely discounted (Smith, Davis, and Fourman, 1960 ; Nordin, 1961). The urinary calcium, on the other hand, unlike the plasma calcium, is well known to be influenced by dietary intake, although the variation from one individual

\footnotetext{
* Research Assistant, University Department of Medicine, Gardiner Institute, Western Infirmary, Glasgow.

t Senior Lecturer, University Department of Medicine, Gardiner Institute, Western Infirmary, Glasgow. Present address: M.R.C. Mineral Metabolism Research Unit, General Infirmary, Leeds.

¥ Temporary Lecturer, University Department of Medicine, Gardiner Institute, Western Infirmary, Glasgow.

$\$$ Chief Technician, University Department of Medicine, Gardiner Institute, Western Infirmary, Glasgow.

|l Present address: University College Hospital, London.
}

to another on the same intake is large (Knapp, 1947) and the normal range of urinary calcium on a free diet or even on a low-calcium diet is relatively wide (Hodgkinson and Pyrah, 1958). It has not been clear how the changes in urinary calcium are brought about by variations in dietary calcium, but one possibility is that they are due to small changes in the filtered load of calcium. Consideration of the magnitude of the filtered load of calcium (about $7 \mathrm{~g}$. daily) and its relation to calcium excretion (about $200 \mathrm{mg}$. daily) indicates that very small changes in the concentration of the plasma ultrafilterable calcium (too small to be detected by routine laboratory methods) could easily account for the variations in urinary calcium normally encountered. The present work was therefore planned to test the possibility that the alteration in urinary calcium brought about by changing from a normal to a low 